\title{
Effect of sea level rise on the overtopping of English coastal defences
}

\author{
Dominic Hames and Ben Gouldby \\ HR Wallingford, Howbery Park, Wallingford, Oxfordshire OX10 8BA, United Kingdom
}

\begin{abstract}
With a rise in sea levels, there is a consequent increase in the risk to coastal communities of the severity and magnitude of flood events. However these increased risks are not spatially consistent, and the type and nature of a coastal defence may influence the change in the risk at a location, and to what extent levels of mitigation may need to be implemented. This paper therefore investigates the impact of the change in risk of coastal flooding around England as a result of sea level rise. It involves the application of components of an existing risk-based coastal flood risk analysis method for a subset of almost 600 defences to rises in sea levels up to $1 \mathrm{~m}$. The resulting analysis shows that overtopping rates increase at a much greater rate for low return period events, which can be in excess of 100 times. The analysis also shows that the change in overtopping rate is a function of the defence type, with the relative changes for sloping defence structures significantly greater than for vertical defence structures
\end{abstract}

\section{Introduction}

Since the start of the 20th century, eustatic sea levels have increased by the order of $0.20-25 \mathrm{~mm}$ Church and White (2011) and University of Colorado, 2021. These are expected to increase in future years, possibly by as much as over $1 \mathrm{~m}$ for the current century (see for example IPCC, 2019). As a consequence, this will result in a greater occurrence of current extreme sea levels and larger wave heights at coastal defences, with a likely increase in the frequency and magnitude of overtopping levels and flooding behind these coastal defences.

Based on multivariate extreme nearshore sea-condition data from a previous study (Gouldby et al. (2017) and HR Wallingford, 2015) and asset information from the Asset Information Management System (Aims) database of the UK Environment Agency (EA) (EA, 2016), this paper therefore investigates the variation in return period overtopping rates for 592 different coastal defence structures across England for relative changes in sea levels up to $1 \mathrm{~m}$. Results are presented for best estimates for different return periods, as well as confidence intervals of $50 \%$ and $95 \%$ for sample return periods for all defence types. This gives confidence levels to changes in overtopping rates for consequent rise in sea levels accounting for isostatic rebound rates for most climate change scenarios at any English coastal location for the rest of this century.

\section{Methodology}

\subsection{Input data sets - sea conditions}

The baseline sea conditions data sets for this study was generated as part of the UK State of the Nation project, (Gouldby et al. (2017) and HR Wallingford, 2015), and comprised of 10,000 year samples of present-day stochastically simulated wave and sea-level conditions at a number of locations around the English coastline. These baseline datasets were generated through the application of a multivariate extreme value model to offshore data based on Met Office $8 \mathrm{~km}$ WaveWatch III hindcast data and a combination of tide gauge data from the UK National Tide Gauge Network and the EA. Accounting for seabed bathymetry and the spatial variation in nearshore sea levels, these conditions were then transformed to the nearshore based on present day conditions using the Swan wave model, Booij et al., (1999), with nearshore predictions at approximately 2500 points at $1 \mathrm{~km}$ spacing. Typically, these nearshore points were located at the $-5 \mathrm{mOD}$ sea bed contour, although a higher level was used if this was considered too far offshore. These wave conditions were then transformed to individual defence structure toes using the methodology proposed by Goda (2010), utilising the nearest nearshore prediction point, with sea levels adjusted for sea level rises up to $1 \mathrm{~m}$. Nearshore beach slopes for use in the nearshore wave modelling were based on the average beach slope in front of the structure toe over a distance approximately equal to one wavelength in this region. The process of evaluating

a Corresponding author: d.hames@hrwallingford.com

DOI 10.3311/FLOODRisk2020.11.13 
nearshore beach profiles and the location of individual structure toes is outlined in HR Wallingford, 2015.

The output of this analysis gave wave and sea level conditions for different sea level increments up to $1 \mathrm{~m}$ for each defence structure considered equivalent to the 10,000 samples noted above. From these different data sets, overtopping rates were determined for all wave and sea level conditions, with return period overtopping rates determined by a countback of the ranked response variables. This process is outlined in more detail in Hames et al., (2019).

\subsection{Input data sets - Asset Information Management System (AIMS) database}

The asset information for this study was based on the EA AIMS database, which is a national inventory of flood risk assets maintained by the Environment Agency. Assets are described as a variety of different types, such as seawalls and embankments, as well as sub-types such as a brick or concrete seawall. In total, there are 62 different sets of defences defined using a categorisation system, Hall et al., (2003) and HR Wallingford, 2004. A variety of information is given, with standardised characteristics given for certain parameters such as structure slope. As a consequence, each defence can be simply discretised so that their performance can be assessed for a variety of different response functions.

Although there are potentially in excess of 8000 assets in this database, most assets were not considered in this paper, with assets removed if they were considered to possibly not fulfil a normal coastal defence function. This included cliffs, seawalls protected by a high shingle ridge as well as structures with low crest heights relative to sea conditions, such as marine lakes. The criteria for which defences to exclude was given in Hames et al., (2020), and was based on current sea levels, not sea levels with any climate change effect added. This process resulted in 592 structures to assess, the locations of which are given in Figure 1. This included 288 defences classified as a coastal embankment (e.g. revetment), 270 as a vertical wall and 34 as a shingle beach.

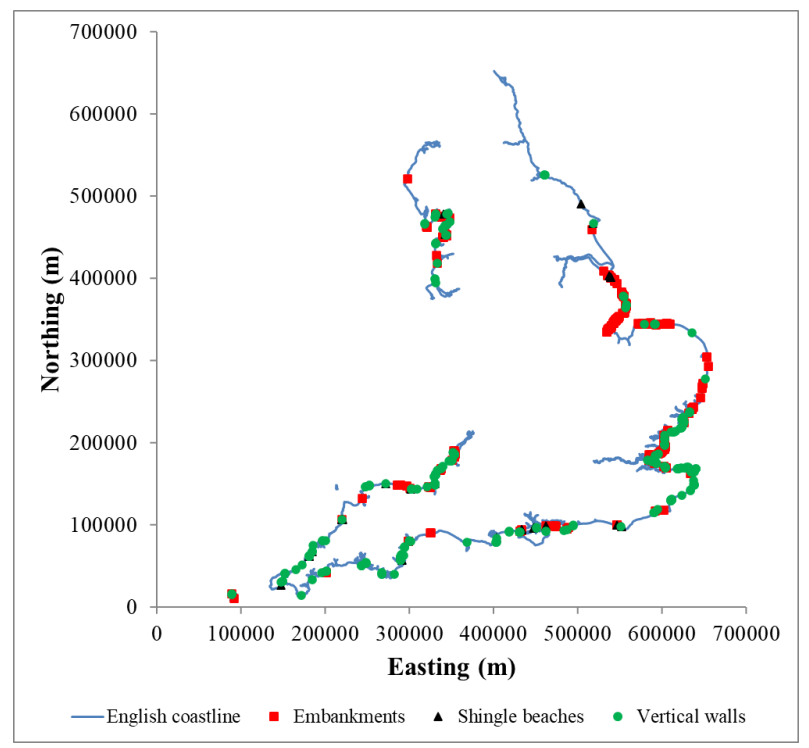

Figure 1. Location of coastal defence structures analysed.

\section{Sea level rise and overtopping rates}

Overtopping rates were considered for each condition in the different datasets for $0.1 \mathrm{~m}$ increments in sea levels from $0.0 \mathrm{~m}$ to $1.0 \mathrm{~m}$. Applying these at increments meant that there was no inference on the rate of sea level rise, its likelihood or the scenario considered, meaning that results would be applicable to any studies with a relative increase in sea levels of up to $1 \mathrm{~m}$. This study did not consider the effect of sea level rise from the offshore point to the nearshore point, as outlined in Section 2.1, however preliminary work on this effect suggests that this affects overtopping rates by less than $5-10 \%$ for a $1 \mathrm{~m}$ increase in sea levels (Hames and Gouldby, 2021). Changes in offshore wave and wind speeds, as well as levels of dependencies between extreme waves and sea levels were also not considered as there is currently little evidence to support quantified estimates of the magnitude or rate of these changes around the coastline of England.

The methodology to determine overtopping rates were based on the recommended methodologies outlined for sloping structures (coastal embankments and shingle beaches) and vertical walls in the EurOtop manual, Pullen et al., (2007). These were chosen as they are considered standard practice for considering overtopping rates across the coastal engineering community in the UK. However, as this study considers the relative change in overtopping rate as sea levels rise, different methodologies would be expected to give comparable results.

\section{Results}

The effect of sea level rise on overtopping rates has been expressed in this paper as the overtopping rate for a specified increase in sea level, relative to the overtopping rate for no increase in sea level. Results are presented for specific return periods for the different structure types, as well as for all defence types combined. For all graphs, the best estimates are given (i.e. the 50th percentile), and where confidence intervals are given, these are for the 50th and 95 th percentiles. Percentiles have been determined by a countback of the ranked overtopping rates for all structures tested.

Figure 2 shows the increase in overtopping rate for different return period events for coastal embankments. This figure indicates that as sea levels rise, overtopping rates increase, and these rates are greater the smaller the return period considered. For example, for a $1 \mathrm{~m}$ rise in sea levels for a 1 in 100 year return period event, overtopping rates increase on average by approximately $10-15$, but this figure is in excess of 120 times for a 1 year return period event. Figure 3 shows the same comparison, but this time for shingle beaches. These results are noted to be comparable to the results for coastal embankments, except for low return period events ( 1 or 2 years), where the increase in overtopping rates are slightly less. 


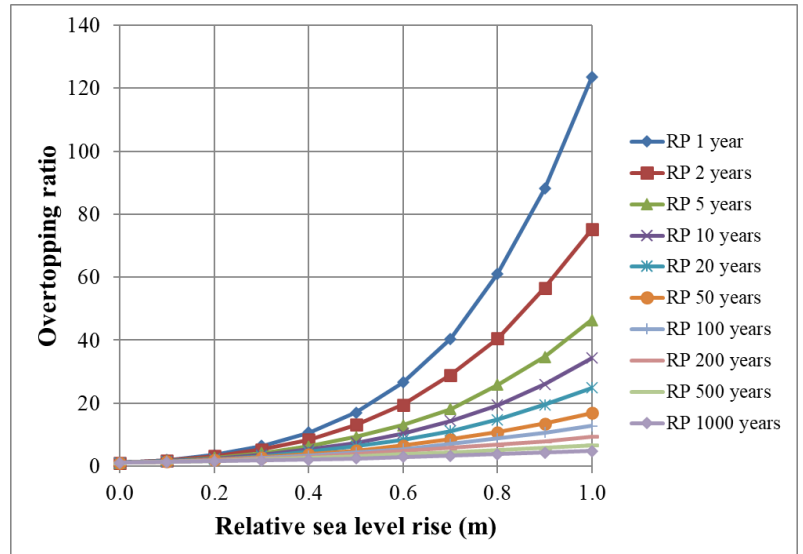

Figure 2. Average rate of change of overtopping rates for coastal embankments.

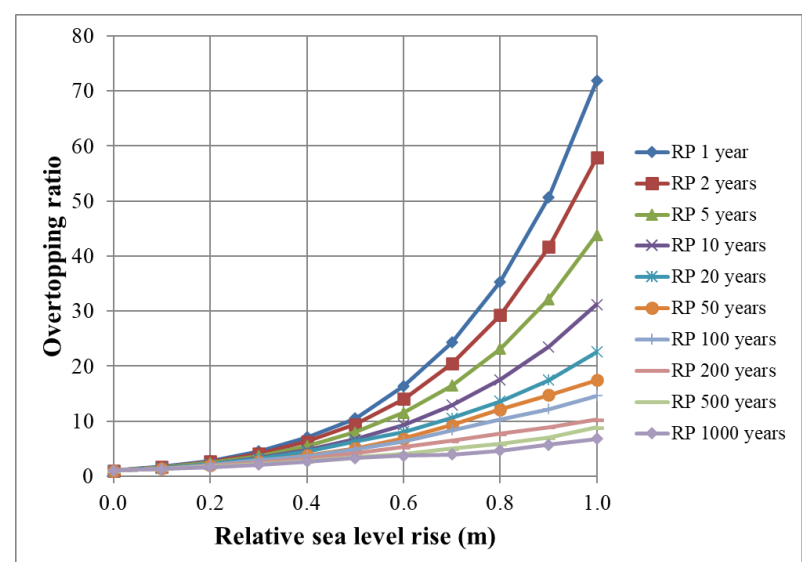

Figure 3. Average rate of change of overtopping rates for shingle beaches.

For Figure 4, vertical seawalls, a similar pattern is observed although the rates of increase are smaller, particularly for small return period events. So, for the same increase in sea levels of $1 \mathrm{~m}$ and a 100 year event, overtopping rates increase by about a factor of about 9 on average, yet this factor only increases to about 13 when considering a 1 year return period event. The reason for these variations relate to the way waves interact with vertical structures, and is discussed in more detail in section 5 .

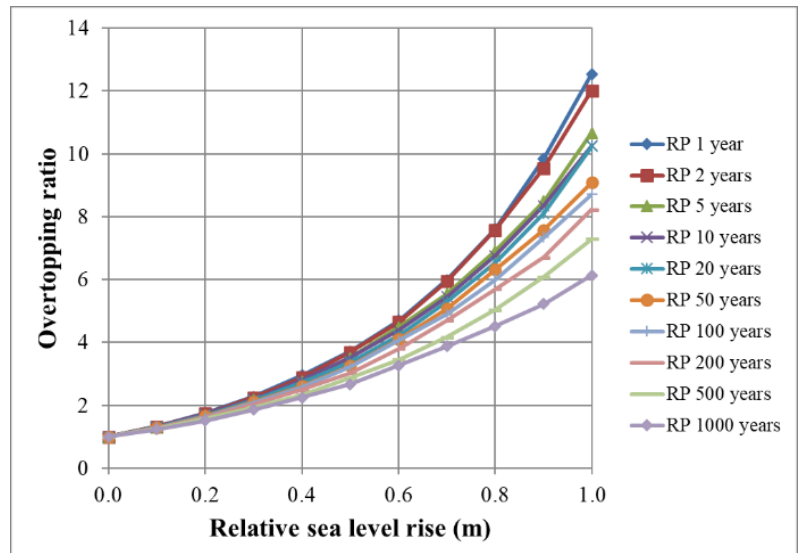

Figure 4. Average rate of change of overtopping rates for vertical walls.
Figure 5 shows the increase in overtopping rate for the 100 year event for all defence types with the 50th and 95th percentile confidence intervals also shown. These indicate that for a $1 \mathrm{~m}$ increase in sea levels, overtopping rates would on average increase by a factor of approximately 11 , although there is a $25 \%$ chance this could increase by a factor of approximately 20 or more, and a $2.5 \%$ chance this could increase by a factor of approximately 65 or more. Figure 6 shows similar results, but this time for the 10 year event. This figure indicates greater overtopping rates, consistent with the results for a smaller return period event as shown in Figures 2, 3 and 4. In this case, for a $1 \mathrm{~m}$ increase in sea levels, overtopping rates would on average increase by about a factor of about 17 , with a $25 \%$ chance this could increase by a factor of approximately 43 or more, and a $2.5 \%$ chance this could increase by a factor of approximately 289 or more. These ratios increase significantly for much smaller return period events. For example, considering data analysed but not shown in this paper for the 1 year return period event, there is a $2.5 \%$ chance that overtopping rates could increase by the order of at least 2400 times for a $1 \mathrm{~m}$ increase in sea levels. However, many if not all of these cases could correspond to very low actual overtopping rates, where an increase of this magnitude may also produce a relatively low overtopping rate.

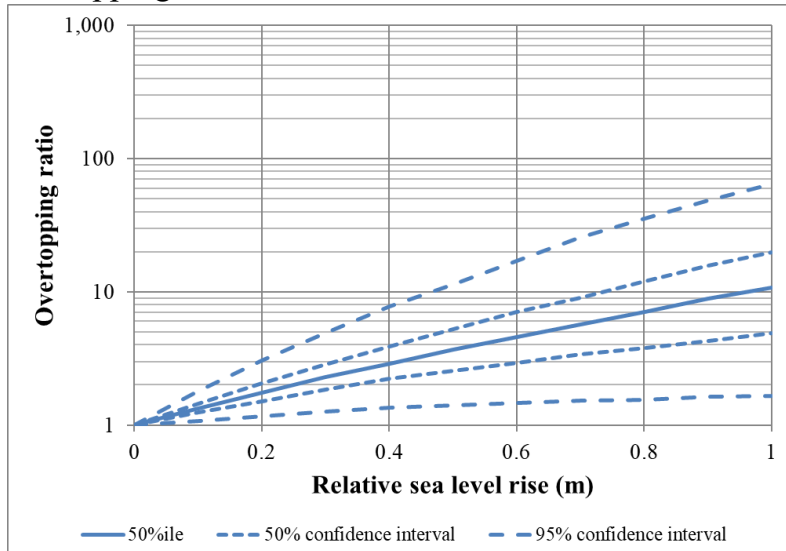

Figure 5. Increase in overtopping rate for the 100 years return period event for all defence types.

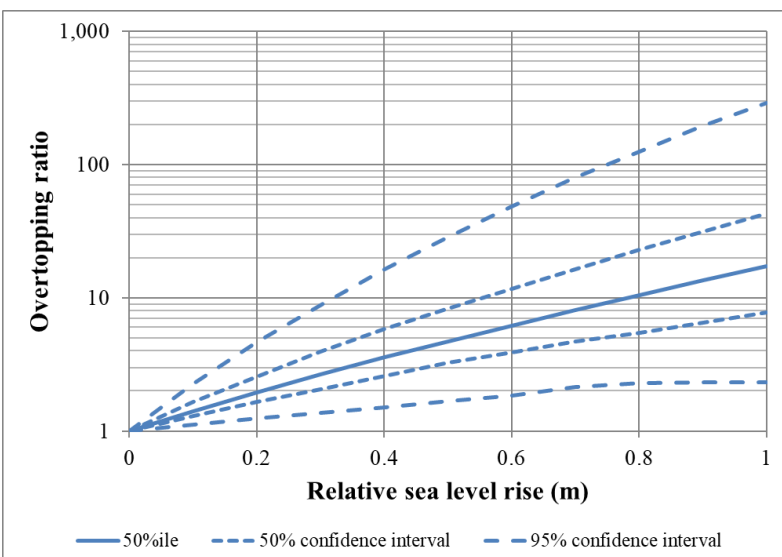

Figure 6. Increase in overtopping rate for the 10 years return period event for all defence types. 


\section{Discussion}

The paper has demonstrated that as sea levels increase, there will likely be a significant increase in levels of overtopping, and that these will be much greater for low return period events. This assumes no changes in other parameters such as wave height, as well as no changes in seabed bathymetry. Although these changes can be significant, they are much more pronounced for sloping structures than for vertical walls. The reason for this relates to the breaking process of waves on vertical seawalls, where at lower water depths certain waves are more likely to break onto the structure (known as impulsive waves). This throws water high up into the air, meaning that overtopping can occur for very high structures. As the water level increases, these waves are more likely to reflect off a structure (known as nonimpulsive waves), with less water thrown into the air and less run-up. This therefore results in less overtopping, even though sea levels are higher. In a Monte Carlo simulation this is mainly not an issue, as waves that move from an impulsive to non-impulsive regime would be replaced by waves that currently break before reaching a structure, and in general as sea levels increase, return period overtopping rates for vertical walls also increase. However, this is not always the case, and theoretically the return period overtopping rate of some structures will actually reduce. This is demonstrated in Figure 7 for a location on the south-east coast of England for a 20 year return period event. This figure shows that as sea levels increase by about $0.5 \mathrm{~m}$, overtopping rates increase. However, as sea levels increase from about $0.5 \mathrm{~m}$ to about $0.7 \mathrm{~m}$, overtopping rates actually reduce. This means that for an increase in sea levels of about $0.5 \mathrm{~m}$, overtopping rates increase by a factor of about 7 , yet reduce by a factor of about 5 as sea levels increase by a further $0.2 \mathrm{~m}$. This will be due to a combination of several factors, although the overriding factor would be the change in the largest waves from impulsive waves to non-impulsive waves at a greater depth as they impact the structure. More work is required to investigate this, although in general, as sea levels increase, levels of overtopping would be expected to increase regardless of the structure type.

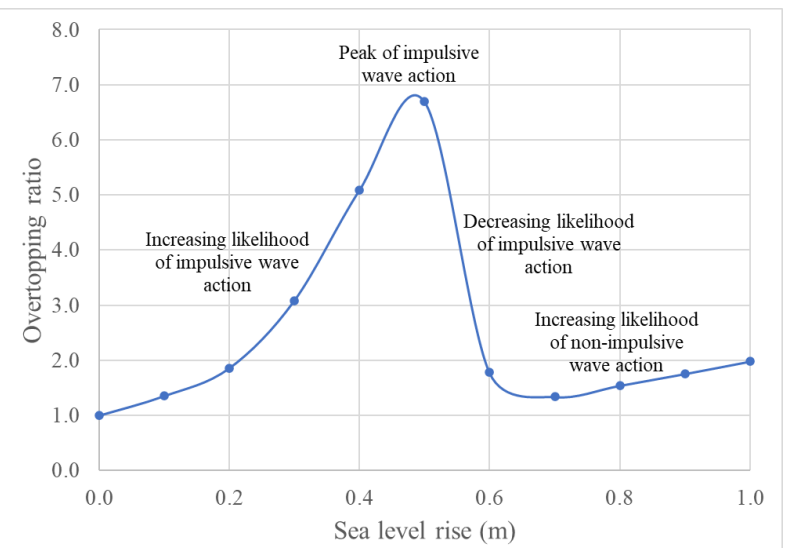

Figure 7. Reduction in overtopping rate for a rise in sea levels for a 20 year return period event for a location in the south-east of England.

\section{Conclusions}

There is clear evidence that sea levels are rising, and with the legacy of many coastal defence structures around the English coastline built without the consideration of these sea level rises, overtopping levels will increase. This means that areas previously at low risk of flooding are likely to flood much more regularly and to greater extents than previously. For areas that already flood relatively frequency, these levels will increase significantly, particularly for locations protected by a sloping structure like a rock-armoured defence.

However, the level of sea level rise is unclear, and estimates of future sea level rise vary based on time periods, scenarios, location and updated studies. This paper has therefore made no assumptions on rates of sea level rise, and therefore the resulting outputs could be used for any of these time periods or scenarios that consider relative sea level rises of up to $1 \mathrm{~m}$. This includes, for example, results presented in UKCP18 (2021), which form the basis of many coastal flood risk assessments around the English coastline.

The analysis is based on a robust national-scale flood risk analysis methodology which involves the application of a multivariate extreme value model to offshore sea conditions. The resulting output of the equivalent of 10,000 years of sea level events transformed to each defence structure toe has been used to assess overtopping rates for each one of these conditions, with sea level rise accounted for by $0.1 \mathrm{~m}$ increments up to $1 \mathrm{~m}$. Sensitivity analysis indicates that the addition of sea level rise to the nearshore, as opposed to the offshore sea conditions has a limited impact on nearshore sea conditions and related overtopping rates.

Considering the overtopping of vertical walls and sloping structures, the analysis has indicated that as sea levels rise, overtopping rates increase and these relative increases are greater for lower return period events. These rates of increase can be significant, however, this may be a result of very low overtopping rates where a significant proportional increase may still result in a very low overtopping rate, and further work is needed in this area. However, for vertical walls the rate of increase is noted to be smaller for vertical seawalls due to the nature of wave breaking on vertical structures. It is also noted that for certain vertical walls, overtopping return period rates could decrease with sea level rise, although further work is require to look into this area.

\section{References}

1. Booij, N., R.C. Ris and L.H. Holthuijsen (1999). A third-generation wave model for coastal regions: 1 . Model description and validation. Journal of Geophysical Research, Oceans 104(C4): 7649-7666.

2. Church, J.A. and N.J. White (2011). Sea-level rise from the late 19 th to the early 21 st century. Surveys in Geophysics 32(4-5): 585-602. 
3. Environment Agency (2016) Environment Agency AIMS Defence Database. Available at https://data.gov.uk/dataset/aims defence (accessed 28/06/16).

4. Goda, Y. (2000) Random seas and design of maritime structures. Advanced Series on Ocean Engineering 15.

5. Gouldby, B., D. Wyncoll, M. Panzeri, M. Franklin, T. Hunt, D. Hames, N. Tozer, P. Hawkes, U. Dornbusch and T. Pullen (2017) Multivariate extreme value modelling of waves, winds and sea levels around the coast of England. Proceedings of the Institution of Civil Engineers - Maritime Engineering 170(1): 320.

6. Hall, J.W., R.J. Dawson, P.B. Sayers, C. Rosu, J.B. Chatterton and R. Deakin (2003) A methodology for national-scale flood risk assessment. Proceedings of the Institution of Civil Engineers - Water Maritime and Engineering 156(3): 235-248.

7. Hames, D., B. Gouldby and P. Hawkes (2019) Evolution of joint probability methods in coastal engineering practice in the UK. Proceedings of the Institution of Civil Engineers - Maritime Engineering 172(2): 45-54.

8. Hames, D., B. Gouldby and P. Hawkes (2020) Investigating the use of joint probability curves in coastal engineering practice. Proceedings of the Institution of Civil Engineers - Maritime Engineering 173(3): 68-78.

9. Hames, D. and B. Gouldby (2021) Impacts of sea level rise on wave overtopping rates around the coast of England. Proceedings of the Institution of Civil Engineers - Maritime Engineering (In press).

10. HR Wallingford (2004) National Flood Risk Assessment 2004: Supported by the RASP HLM plus: Methodology. September 2004. Report for the Environment Agency.

11. HR Wallingford (2015) State of the Nation: Coastal Boundary Conditions Report. Report for the Environment Agency, Report Number 30, Reference MCR5389-30-R00-01.

12. IPCC (2019) Sea level rise and implications for lowlying islands, coasts and communities. In: IPCC Special Report on the Ocean and Cryosphere in a Changing Climate [Pörtner, H.O. D.C. Roberts, V. Masson-Delmotte, P. Zhai, M. Tignor, E. Poloczanska, K. Mintenbeck, M. Nicolai, A. Okem, J. Petzold, B. Rama, N. Weyer (eds.)]. In press.

13. Pullen, T., N.W.H. Allsop, T. Bruce, A. Kortenhaus, H. Schüttrumpf and J.W. Van Der Meer (2007) EurOtop: Wave Overtopping of Sea Defences and Related Structures: Assessment Manual.

14. UKCP18 (2021) UK Climate Projections (UKCP). Available at: https://www.metoffice.gov.uk/research/approach/coll aboration/ukcp/index (Accessed: 24 February 2021).

15. University of Colorado Sea Level Research Group (2021) Most Recent GMSL Release. Available at: https://sealevel.colorado.edu/ (Accessed: 24 February 2021). 